STUDIEN UBER DIE DEUTSCHE GESCHICHTSWISSENSCHAFT BAND 1 



\section{Studien über die}

deutsche Geschichtswissenschaft Band 1

Die deutsche Geschichtswissenschät vom Bèginn des 19. Jahrhunderts bis zur Reichseinigung von oben

Herausgegeben von

JOACHIM STREISAND

deb

verlag das europäische buch 
Dieser Band erschien unter der Redaktion von Hans Schleier zuerst 1969 als Band 20, Reihe 1: "Allgemeine und deutsche Geschichte", der Schriften des Instituts fur Geschichte bei der Deutschen Akademie der Wissenschaften zu Berlin.

das europäische buch literaturvertrieb gmbh westberlin

ISBN 3-920 303-49-0

(C) 1969 by Akademie Verlag

Berlin DDR

Printed in the German

Democratic Republic

1380 